Epidemiology

\title{
Functional outcomes and oncological fatigue among older cancer patients: a cross-sectional study
}

\author{
Luz Alejandra Lorca ${ }^{1}$ (D), Cinara Sacomori ${ }^{2} *$ (D), Rodrigo Vidal-Labra ${ }^{2}$ (D), \\ Nathalie Paloma Cavieres ${ }^{2}$ D, Kamilla Zomkowski $^{3}$ \\ ${ }^{1}$ Hospital del Salvador, Servicio de Salud Metropolitano Oriente, Santiago, Chile; ${ }^{2}$ Universidad \\ Bernardo O'Higgins, Escuela de Kinesiología, Santiago, Chile; ${ }^{3}$ Universidade do Sul de Santa \\ Catarina, Departamento de Fisioterapia, Palhoça, SC, Brazil.
}

Associate Editor: Angelina Zanesco, Departamento de Educação Física, Instituto de Biociências, Universidade Estadual Paulista "Júlio de Mesquita Filho", Rio Claro, SP, Brasil.

\begin{abstract}
Aim: To characterize functional outcomes and oncological fatigue in older cancer patients, and verify the relation of these outcomes with age, number of hospitalizations, and falls within 12-months. Methods: Cross-sectional study involving 116 older adults with cancer undergoing treatment in a hospital in Santiago de Chile. Participants were assessed for independence on the activity of daily living (Barthel index), functional mobility with "timed up and go" (TUG) test, handgrip strength with a Baseline ${ }^{\circledR}$ Hydraulic Hand Dynamometer, and fatigue with Brief Fatigue Inventory. Information about the number of falls and hospitalizations from the previous 12-months was also collected. Results: $21.6 \%$ had experienced at least one fall during the previous 12 -months, and $52 \%$ had been hospitalized over the same period. Handgrip strength was below the cut-off thresholds for older adults and $78.4 \%$ were classified with the risk of falls according to the TUG test. Forty-nine percent of participants experienced moderate fatigue, and $58 \%$ were dependent to perform activities of daily living. There was a correlation of TUG results with age $(r=0.204 ; p=0.028)$. Conclusions: Older adults with cancer in our study experienced moderate fatigue, a high dependence to perform activities of daily living, especially those associated with mobility, dressing, and bladder or bowel function. Older adults with cancer are more likely to develop functional decline which leads to increased dependency or death. The data suggests they present functional impairment. Physical activity interventions would benefit this population.
\end{abstract}

Keywords Geriatric assessment, functional decline, geriatric complications, neoplasms.

\section{Introduction}

According to the World Health Organization (WHO), the prevalence of older adults aged over 60 years will increase from $11 \%$ to $22 \%$ by $2050^{1}$. Growing older increases the odds of having a cognitive and/or functional impairment, including higher rates of developing chronic nontransmissible diseases, like cancer ${ }^{2}$. About $60 \%$ of malignancies and $70 \%$ of all deaths by cancer occur among adults over 65 years old. In 2018, 18 million people were diagnosed with cancer around the world ${ }^{3}$. Multiple available treatments for cancer, as well as tumor damages depending on location and spread, may generate several collateral side effects like fatigue, peripheral neuropathies, and functional impairments ${ }^{4}$.

Older cancer patients might be at higher risk to present fatigue and functional decline compared to those without cancer. The literature supports comprehensive geriatric assessment including functional outcome measures like the Timed Up and Go (TUG) test, cognitive status via mini-mental state examination ${ }^{5,6}$, the identification of the level of dependence in daily activities ${ }^{7,8}$, as well as to screen for handgrip strength level, which is considered an important predictor of nutritional status, mortality and functional status as shown in previous studies ${ }^{9}$.

Functional impairments are highly prevalent among older cancer survivors. A recent epidemiological study showed that $68.6 \%$ of the cancer survivors had moderate to severe functional limitation due to pain, $48.3 \%$ moderate to severe functional limitation due to emotional distress, and approximately $10 \%$ reported severe functional limitation due to co-occurring symptoms of pain and emotional distress ${ }^{10}$. Severe functional limitation was more common among octogenarians, stage IV disease at diagnosis, and for those with lung cancer ${ }^{10}$. After cancer diagnosis, $45.0 \%$ of the older adults showed limitations on their instrumental activities of daily life and $12.8 \%$ on basic activities of daily life ${ }^{11}$.

Physical frailty in older adults is characterized by diminished strength, endurance, and physiologic function that increases an individual's vulnerability for developing increased dependency and/or death ${ }^{7}$. Previous studies 
have shown that $39 \%$ of older patients cannot manage their care after hospital discharge and that mobility disabilities are associated with a higher risk of mortality among older adults ${ }^{6}$. Cancer patients might have an increased functional decline because of tumor location damages and treatment toxicities. However, there is limited information regarding functional outcomes and oncological fatigue among Latin-American older cancer survivors. Therefore, the present study aims to characterize functional outcomes and oncological fatigue in Chilean older cancer patients, and verify the relation of these outcomes with age, number of hospitalizations, and falls within 12-months.

\section{Methods}

\section{Study design and population}

This is an observational cross-sectional study of 116 older cancer patients treated at Hospital del Salvador, Santiago de Chile, Chile. Consecutive sampling was used to select the cancer patients who underwent clinical assessment at institutional polyclinics, including the palliative care and pain relief unit. The present study was approved by the Ethics Committee of Servicio de Salud Metropolitano Oriente (Approval date: September $6^{\text {th }}, 2016$ ). Written informed consent was obtained from all participants.

The eligibility criteria included cancer patients aged 60 years or older who were being treated for malignancy and were in out-patient medical appointments at Hospital del Salvador. The participants were excluded if they were illiterate, did not accept to participate in the present study, were hospitalized or institutionalized, or had cognitive or auditive impairments that could compromise the understanding of evaluations, a score of above 13.0 on minimental state examination (MMSE) was used as a cut-off of good cognitive status. In addition, being able to walk and not using any walking aid was required to perform the Timed Up and Go test.

\section{Instruments}

The functional outcomes considered in this study were: handgrip strength, basic activities of daily living, functional mobility (gate speed), and the number of falls in the last year. In addition, we used some questions about sociodemographic and clinical characteristics obtained from Hospital medical records: age, gender, educational level, marital status, cohabitation, cancer diagnosis, cancer treatments received, and comorbidities. The number of falls and number of hospitalizations in the last year were obtained by self-report. The number of hospitalizations was double-checked with a medical record.

\section{Handgrip strength}

For assessing handgrip strength, a digital dynamometer (Baseline ${ }^{\circledR}$ Hydraulic Hand Dynamometer) was used on the dominant hand. The participant was kept seated in a chair with their arm in adduction and elbow flexed at $90^{\circ}$, the forearm in the neutral position, and the hand positioned with $15-30^{\circ}$ of extension and $0-15^{\circ}$ of ulnar deviation. Each participant was asked to perform three trials with maximum effort to squeeze the dynamometer, with a 30-s break between each trial, a mean was obtained three trials ${ }^{12}$.

Independence in daily activities

Functional independence was assessed using the Barthel Index ${ }^{13}$, which values the independence of a patient in ten daily activities: feeding, dressing, bathing, grooming, chair/bed transfers, using stairs, mobility, using the toilet, and bladder and bowel control. The general score ranges from 0 (totally dependent) to 100 (independent). Patients are classified into five categories according to their scores: totally dependent (0-20), severe dependence (21-60), moderate dependence (6190), mild dependence (91-99), and independent (100). The Barthel Index was considered reliable for using in older adults ${ }^{14}$.

Functional mobility

Functional mobility was assessed considering gait speed obtained from the Timed Up and Go test (TUG) only among patients that could walk without any aid. It is a useful test for risk of fall assessment. This test consists of verbal instruction to get up from a chair, walk at a comfortable and safe pace to a line on the floor three meters away, turn and walk back to sit again on the chair. The time of the task is registered, and the participant uses its regular footwear or walking aid. This test was validated ${ }^{15}$ and the cut-off time to identify fall risk in older adults is higher than ten seconds ${ }^{16}$.

Oncological fatigue

The fatigue assessment was performed using the Brief Fatigue Inventory (BFI) developed and validated in the United States ${ }^{17}$, and recently validated in Chile ${ }^{18}$. This is a nine-item instrument with scales ranging from one to ten. Three items provide the severity level, whereas the patient grades their fatigue at the moment of assessment, the usual (average level from last 24-hours), and the worst fatigue (if the sensation is more acute than the last 24hours). The score ranges from 0 (no fatigue) to 10 (as bad as you can imagine). The other six items inform to what extent fatigue interferes in other areas of life, including general activity, mood, walking ability, normal work (includes both work outside the home and daily chores), relations with other people, and enjoyment of life. Each item is measured with a score ranging from 0 (does not interfere) to 10 (completely interferes). To categorize the fatigue severity the item regarding the "worst fatigue" is used, in which the patients are classified into three groups: 
mild (score 1-3), moderate (score 4-6) and severe (score 710) ${ }^{19}$.

\section{Data analysis}

The data were analysed on Statistical Package for Social Science (SPSS) IBM version 23.0. For descriptive statistics, we used frequencies, mean, median, standard deviation, and interquartile range. A Mann-Whitney test was performed to compare the differences between gender and a Spearman Correlation test was used to identify bivariate correlations between functional status, balance, handgrip strength, and fatigue with age, number of hospitalizations and falls within 12-months. A confidence interval of $95 \%$ was adopted.

\section{Results}

\section{Patient characteristics}

One hundred and sixteen older cancer patients were enrolled in the study, with an average age of $69.3 \pm$ 6.8 years old and a MMSE score of $17.6 \pm 1.6$. Sixty-six $(56.8 \%)$ of them were women. In general, participants were married $(50 \% ; \mathrm{n}=58)$ and lived with their family $(81 \% ; \mathrm{n}=94)$. Regarding the level of education, the majority had not finished high school $(25.9 \% ; n=30)$ (Table 1).

Table 1 - Sociodemographic characteristics of enrolled older cancer patients.

\begin{tabular}{lccc}
\hline & $\begin{array}{c}\text { All participants } \\
(\mathbf{n}=\mathbf{1 1 6})\end{array}$ & $\begin{array}{c}\text { Women } \\
(\mathbf{n}=\mathbf{6 6})\end{array}$ & $\begin{array}{c}\text { Men } \\
(\mathbf{n}=\mathbf{5 0})\end{array}$ \\
& $\mathbf{n}(\mathbf{\%})$ & $\mathbf{n}(\mathbf{\%})$ & $\mathbf{n}(\mathbf{\%})$ \\
\hline $\begin{array}{l}\text { Educational level } \\
<8 \text { years of study }\end{array}$ & $27(23.3)$ & $14(21.2)$ & $13(26.0)$ \\
$>8$ years of study & $89(76.7)$ & $52(78.8)$ & $37(74.0)$ \\
Marital status & & & \\
Single & $17(14.7)$ & $12(18.5)$ & $5(10)$ \\
Married & $58(50)$ & $30(45.5)$ & $28(56)$ \\
Stable union & $3(2.6)$ & $2(3)$ & $1(2)$ \\
Separated & $9(7.8)$ & $4(6.1)$ & $5(10)$ \\
Divorced & $5(4.3)$ & $3(4.5)$ & $2(4)$ \\
Widow & $22(19.0)$ & $15(22.7)$ & $7(14)$ \\
Cohabitation & & & \\
Family & $94(81)$ & $55(83.3)$ & $39(78)$ \\
Caregivers & $3(2.6)$ & $1(1.5)$ & $2(4)$ \\
Nursing home & $13(11.2)$ & $6(9.1)$ & $7(14)$ \\
Alone & $3(2.6)$ & $2(3)$ & $1(2)$ \\
Others & $1(0.9)$ & $1(1.5)$ & - \\
\hline
\end{tabular}

\section{Cancer characteristics}

The most common cancer among all participants was hematological malignancies $(21.6 \% ; \mathrm{n}=25)$, while breast cancer was the most common among women $(30.3 \% ; n=20)$ and hematological malignancy was most common among men $(22 \% ; n=11)$. Regarding cancer therapies, chemotherapy was the most common type of treatment received among all participants $(53.4 \% ; \mathrm{n}=70)$, and among men and women. In terms of comorbidities, musculoskeletal complications $(78.4 \% ; n=90)$, followed by arterial hypertension $(53.4 \% ; \mathrm{n}=62)$, were the most common among all participants (Table 2).

\section{Functional outcomes}

In the present study, twenty-five participants $(21.6 \%)$ had experienced at least one fall during the previous 12 months. As for the hospitalizations from the last 12 -months, fifty-nine participants $(51 \%)$ had at least one

Table 2 - Cancer diagnosis, stage, and treatments.

\begin{tabular}{|c|c|c|c|}
\hline & $\begin{array}{l}\text { All participants } \\
\begin{array}{c}(\mathrm{n}=116) \\
\text { n }(\%)\end{array}\end{array}$ & $\begin{array}{c}\text { Women } \\
(\mathrm{n}=66) \\
n(\%)\end{array}$ & $\begin{array}{c}\text { Men } \\
(\mathrm{n}=\mathbf{5 0}) \\
\mathbf{n}(\%)\end{array}$ \\
\hline \multicolumn{4}{|l|}{ Cancer diagnosis } \\
\hline Breast & $20(17.2)$ & $20(30.3)$ & - \\
\hline Colorectal & $12(11.2)$ & $5(7.5)$ & $7(14)$ \\
\hline Gastric & $4(3.4)$ & $1(1.5)$ & $3(6)$ \\
\hline Hematologic & $25(21.6)$ & $14(21.0)$ & $11(22)$ \\
\hline Lung & $6(5.2)$ & $3(4.5)$ & $3(6)$ \\
\hline Gynecologic & $5(4.3)$ & $5(7.5)$ & - \\
\hline Head and Neck & $9(7.8)$ & $5(7.5)$ & $4(8)$ \\
\hline Prostate & $10(8.6)$ & - & $10(20)$ \\
\hline $\begin{array}{l}\text { Skin (melanoma and non- } \\
\text { melanoma) }\end{array}$ & $10(8.6)$ & $7(10.5)$ & $3(6)$ \\
\hline Others & $15(12.1)$ & $6(9)$ & $9(18)$ \\
\hline \multicolumn{4}{|l|}{ Treatment received } \\
\hline Chemotherapy & $71(53.4)$ & $40(37.9)$ & $31(62)$ \\
\hline Radiation therapy & $57(34.3)$ & $31(47)$ & $26(52)$ \\
\hline Endocrine therapy & $5(3.0)$ & $3(4.5)$ & $2(4)$ \\
\hline Surgery & $58(50.0)$ & $34(51.5)$ & $24(48)$ \\
\hline \multicolumn{4}{|l|}{ Comorbidities } \\
\hline $\begin{array}{l}\text { Respiratory complica- } \\
\text { tions }\end{array}$ & $17(10.2)$ & $12(18.2)$ & $5(10)$ \\
\hline Mood disorders & $52(44.8)$ & $32(48.5)$ & $20(40)$ \\
\hline $\begin{array}{l}\text { Musculoskeletal compli- } \\
\text { cations }\end{array}$ & $91(78.4)$ & $54(81.8)$ & $37(74)$ \\
\hline Arterial hypertension & $62(53.4)$ & $36(54.5)$ & $26(52)$ \\
\hline Diabetes Mellitus & $22(19.0)$ & $12(18.2)$ & $10(20)$ \\
\hline Cardiac complications & $12(10.3)$ & $4(6.1)$ & $8(16)$ \\
\hline $\begin{array}{l}\text { Cerebrovascular compli- } \\
\text { cations }\end{array}$ & $7(6.0)$ & $3(4.5)$ & $4(8)$ \\
\hline
\end{tabular}


hospitalization. Regarding gait mobility, most of the participants were classified at risk of falling $(78.4 \% ; n=91)$, because they took more than 10 seconds to perform the TUG test, and this frequency was even higher among women $(80.3 \% ; \mathrm{n}=53)$ (Table 3$)$.

Almost $80 \%(n=61)$ of participants had mild to moderate dependence on basic daily activities, the frequencies were similar in both genders. Activities like chair/bed transfers $(11.2 \% ; \mathrm{n}=13)$, mobility $(25.4 \%$; $\mathrm{n}=30)$, and climbing stairs $(51.7 \% ; \mathrm{n}=60)$ were those that required more assistance (Table 3 ).

\section{Oncological fatigue}

Fatigue was highly prevalent, as $49.1 \%(\mathrm{n}=57)$ of participants reported moderate fatigue. The mean of the Brief Fatigue Inventory Score was $41.2(\mathrm{SD}=18.9)$ whose scores range from 0 (no fatigue) to 90 (the highest fatigue).

Table 3 - Characteristics of the functional status of older adults with cancer.

\begin{tabular}{|c|c|c|c|}
\hline & $\begin{array}{c}\text { All participants }(\mathrm{n}=116) \\
\text { n (\%) }\end{array}$ & $\begin{array}{c}\text { Women }(\mathrm{n}=66) \\
\mathrm{n}(\%)\end{array}$ & $\begin{array}{c}\text { Men }(n=50) \\
n(\%)\end{array}$ \\
\hline \multicolumn{4}{|l|}{ Number of falls from last 12-months } \\
\hline None & $91(78.4)$ & $49(74.2)$ & $42(84.0)$ \\
\hline 1 & $22(19.0)$ & $14(21.2)$ & $8(16.0)$ \\
\hline 2 & $2(1.7)$ & $2(3.0)$ & - \\
\hline 3 & $1(0.9)$ & $1(1.5)$ & - \\
\hline \multicolumn{4}{|l|}{ Number of hospitalizations from last 12 -months } \\
\hline None & $56(48.3)$ & $36(54.5)$ & $20(40.0)$ \\
\hline 1 & $46(39.7)$ & $22(33.3)$ & $24(48.0)$ \\
\hline 2 & $9(7.8)$ & $5(7.6)$ & $4(8.0)$ \\
\hline 3 or more & $4(3.5)$ & $3(4.5)$ & $1(2.0)$ \\
\hline Gait mobility: fall risk (TUG test) ${ }^{\dagger}$ & $91(78.4)$ & $53(80.3)$ & $38(76.0)$ \\
\hline \multicolumn{4}{|l|}{ Oncologic fatigue } \\
\hline None & $8(6.9)$ & $3(4.5)$ & $5(10.0)$ \\
\hline Mild & $19(16.3)$ & $9(13.6)$ & $10(20.0)$ \\
\hline Moderate & $57(49.1)$ & $34(51.5)$ & $23(46.0)$ \\
\hline Severe & $32(27.6)$ & $20(30.2)$ & $12(24.0)$ \\
\hline \multicolumn{4}{|c|}{ Independence on Activities of Daily Living (Barthel) } \\
\hline Totally dependent $(0-20)$ & $0(0.0)$ & $0(0.0)$ & $0(0.0)$ \\
\hline Severe dependent (21-60) & $6(5.2)$ & $4(6.1)$ & $2(4.0)$ \\
\hline Moderate dependent (61-90) & $30(52.9)$ & $17(25.8)$ & $13(26.0)$ \\
\hline Mild dependent (91-99) & $31(26.7)$ & $18(27.3)$ & $13(26.0)$ \\
\hline Independent (100) & $49(42.2)$ & $27(40.9)$ & $22(44.0)$ \\
\hline \multicolumn{4}{|l|}{ Feeding } \\
\hline Unable & - & - & - \\
\hline Needs help cutting, spreading butter & - & - & - \\
\hline Independent (food provided in reach) & $116(100)$ & $66(100)$ & $50(100)$ \\
\hline \multicolumn{4}{|l|}{ Bathing } \\
\hline Dependent & $7(6.0)$ & $5(7.6)$ & $2(4.0)$ \\
\hline Independent (or in the shower) & $107(92.2)$ & $59(89.4)$ & $48(96.0)$ \\
\hline \multicolumn{4}{|l|}{ Dressing } \\
\hline Dependent & $1(0.9)$ & $1(1.5)$ & - \\
\hline Needs help, but can do half unaided & $14(12.1)$ & $10(15.2)$ & $4(8.0)$ \\
\hline Independent (including buttons, zips, laces) & $101(87.1)$ & $55(83.3)$ & $46(92.0)$ \\
\hline \multicolumn{4}{|l|}{ Grooming } \\
\hline Needs help with personal care & $2(1.7)$ & $1(1.5)$ & $1(2.0)$ \\
\hline
\end{tabular}


Table 3 - continued

\begin{tabular}{|c|c|c|c|}
\hline & $\begin{array}{c}\text { All participants }(n=116) \\
\text { n (\%) }\end{array}$ & $\begin{array}{c}\text { Women }(n=66) \\
n(\%)\end{array}$ & $\begin{array}{c}\text { Men }(n=50) \\
\text { n (\%) }\end{array}$ \\
\hline Independent face/hair/teeth/shaving (implements provided) & $114(98.3)$ & $65(98.5)$ & $49(98.0)$ \\
\hline \multicolumn{4}{|l|}{ Bowel } \\
\hline Incontinent (or needs to be given an enema) & $1(0.9)$ & - & $1(2.0)$ \\
\hline Occasional accident (max once per/24 hours) & $7(6.0)$ & $2(3)$ & $5(10.0)$ \\
\hline Continent (for over 7 days) & $108(93.1)$ & $64(97)$ & $44(88.0)$ \\
\hline \multicolumn{4}{|l|}{ Bladder } \\
\hline Incontinent, or catheterized and unable to manage & $1(0.9)$ & - & $1(2.0)$ \\
\hline Occasional accident (max once per/24 hours) & $9(7.8)$ & $5(7.6)$ & $4(8.0)$ \\
\hline Continent (for over 7 days) & $106(91.4)$ & $61(92.4)$ & $45(90.0)$ \\
\hline \multicolumn{4}{|l|}{ Toilet use } \\
\hline Dependent & - & - & - \\
\hline Needs some help, but can do something alone & $8(6.9)$ & $5(7.6)$ & $3(6.0)$ \\
\hline Independent (on and off, dressing, wiping) & $108(93.1)$ & $61(92.4)$ & $47(94.0)$ \\
\hline \multicolumn{4}{|l|}{ Chair-bed Transfers } \\
\hline Unable - no sitting balance & $1(0.9)$ & $1(1.5)$ & - \\
\hline Major help (one or two people, physical) & $4(3.4)$ & $2(3)$ & $2(4.0)$ \\
\hline Minor help (verbal or physical) & $8(6.9)$ & $7(10.6)$ & $1(2.0)$ \\
\hline Independent & $103(88.8)$ & $56(84.8)$ & $47(94.0)$ \\
\hline \multicolumn{4}{|l|}{ Mobility } \\
\hline Immobile & $5(4.3)$ & $3(4.5)$ & $2(4.0)$ \\
\hline Wheelchair independent including corners & $6(5.2)$ & $4(6.1)$ & $2(4.0)$ \\
\hline Walks with help of one person (verbal or physical) & $19(16.4)$ & $14(21.2)$ & $5(10.0)$ \\
\hline Independent (but may use aid, e.g. stick) & $86(74.1)$ & $45(68.2)$ & $41(82.0)$ \\
\hline \multicolumn{4}{|l|}{ Stairs } \\
\hline Unable & $5(4.3)$ & $2(3.0)$ & $3(6.0)$ \\
\hline Needs help (verbal, physical, carrying aid) & $55(47.4)$ & $33(50.0)$ & $22(44.0)$ \\
\hline Independent up and down & $56(48.3)$ & $31(47.0)$ & $25(50.0)$ \\
\hline
\end{tabular}

${ }^{\dagger}$ Cut-off TUG (Timed Up and Go) > 10 seconds.

\section{Outcomes and gender}

Regarding the outcome differences between genders in the present study, the handgrip strength test produced higher scores among men, with a median of $25.76 \mathrm{kgf}$ (9.17) compared to the women ( $p<0.001)$ (Table 4). For other functional outcomes, there was no statistical difference between men and women.

\section{Outcomes correlation}

When analysing the correlation of TUG, Barthel Index, Brief Fatigue Inventory, and handgrip strength, with age and number of falls and hospitalizations within the previous 12-months, the only TUG was found to have a mild correlation with age $(\mathrm{p}=0.028)$ (Table 5).

Gait mobility (seconds to perform TUG) was negatively correlated to Barthel index (rho $=-0.302)$ and positively with oncological fatigue $($ rho $=0.294)$. Barthel index was correlated positively with handgrip strength $($ rho $=0.239)$ and negatively with oncological fatigue (rho $=-0.394)$.

\section{Discussion}

This study assessed functional outcomes and fatigue among older patients who were being treated for cancer and were in out-patient medical appointments. We identified that they presented functional impairments, as $58 \%$ were dependent to perform activities of daily living. Those activities that required major aid were chair/bed transfers, mobility, and climbing stairs. Handgrip strength was below the reference values for their age and $78.4 \%$ were classified with the risk of falls according to the TUG test. Meanwhile, fatigue was highly prevalent among men and women, the intensity of fatigue was considered moderate. 
Table 4 - Comparison of TUG, handgrip strength, functional status, and fatigue between older men and older women with cancer $(\mathrm{n}=116)$.

\begin{tabular}{|c|c|c|c|c|c|c|c|}
\hline & \multicolumn{2}{|c|}{ All participants $(n=116)$} & \multicolumn{2}{|c|}{ Women $(n=66)$} & \multicolumn{2}{|c|}{$\operatorname{Men}(n=50)$} & \multirow[b]{2}{*}{ p value } \\
\hline & X (SD) & Median (IQR) & X (SD) & Median (IQR) & X (SD) & Median (IQR) & \\
\hline Timed up and Go (s) & $14.1(5.8)$ & $12.0(8.0)$ & $14.3(6.3)$ & $12.0(8.0)$ & $13.8(5.2)$ & $12.0(8.0)$ & $0.729 \ddagger$ \\
\hline Handgrip strength (kgf) & $23.0(6.6)$ & $21.7(9.3)$ & $20.9(6.0)$ & $20.3(6.9)$ & $25.9(6.8)$ & $25.7(9.2)$ & $<0.001 \ddagger$ \\
\hline Barthel index score & $94.0(9.2)$ & $95.0(10.0)$ & $91.7(12.9)$ & $95.0(10.0)$ & $92.7(12.5)$ & $95.0(10.0)$ & $0.743 \ddagger$ \\
\hline Brief Fatigue Inventory score & $40.4(19.9)$ & $41.0(27.5)$ & $43.7(18.6)$ & $43.0(21.3)$ & $38.0(19.1)$ & $39.5(24.3)$ & $0.091 \dagger$ \\
\hline
\end{tabular}

$\dagger$ : independent t-test; $\neq$ : Mann-whitney U test; X: mean; SD: standard deviation; IQR: interquartile range.

Table 5 - Correlations between functional outcome measures, age, number of falls, and hospitalizations within 12-months (n = 116).

\begin{tabular}{|c|c|c|c|c|c|c|c|}
\hline & $\begin{array}{c}\text { TUG\# } \\
(\rho)\end{array}$ & $\begin{array}{c}\text { Barthel Index } \\
(\rho) \\
\end{array}$ & $\begin{array}{c}\text { Handgrip } \\
\text { strength }(\rho)\end{array}$ & $\begin{array}{c}\text { Fatigue Score } \\
(\rho)\end{array}$ & $\begin{array}{l}\text { Age } \\
(\rho)\end{array}$ & $\begin{array}{c}\text { Number of falls }(12- \\
\text { months })(\rho)\end{array}$ & $\begin{array}{c}\text { Number of hospitalizations (12- } \\
\text { months) }(\rho)\end{array}$ \\
\hline TUG\# & NA & $-0.302 *$ & -0.139 & $0.294^{*}$ & $0.204^{*}$ & 0.031 & 0.083 \\
\hline Barthel index & $-0.302 *$ & NA & $0.239 *$ & $-0.394^{*}$ & -0.124 & -0.055 & -0.075 \\
\hline $\begin{array}{l}\text { Handgrip } \\
\text { strength }\end{array}$ & -0.139 & $0.239^{*}$ & NA & -0.117 & 0.161 & -0.003 & 0.081 \\
\hline Fatigue score & $0.294^{*}$ & $-0.394^{*}$ & -0.117 & NA & 0.031 & 0.061 & 0.028 \\
\hline
\end{tabular}

$\rho$ : spearman's rho test; *significant correlations at $\mathrm{p}<0.05$; \#TUG: Timed up and Go in seconds. NA: not applicable.

In a Mexican study with 543 older adults (average age 76 years old) without cancer, about $15 \%$ of them were dependent when performing daily activities ${ }^{20}$. In the present study, the rates are higher, as more than half of our older adults with cancer were dependent on their daily activities, especially those involving chair/bed transfers, mobility, and climbing stairs. According to a previous Chilean study involving 975 older adults with an average age of 70 years-old, functional limitations can be predictors for mortality, morbidity, and disability for older adults $^{21}$.

In this study, handgrip strength levels were below the cut-off thresholds for men and women, which suggests they might have or develop sarcopenia. Men had a median of $25.87 \mathrm{kgf}$, while women had a median of $22.63 \mathrm{kgf}$, and the cut-off is $32 \mathrm{kgf}$ for men and $22 \mathrm{kgf}$ for women ${ }^{22}$. A previous Indonesian study with 352 participants with an average age of 69 years-old showed that low handgrip strength is associated with malnutrition and age of above 75 years-old ${ }^{23}$. A study with 104 older and young cancer patients in Turkey, showed a moderate relation between handgrip strength and lean body mass ${ }^{24}$.

Despite the high probabilities of falls $(78.4 \%)$, in this study, when considering the time of performing the TUG test, there was a lower quantity of older cancer patients who reported falls within the preceding 12months $(21.6 \%)$. This result might be explained by a previous systematic review with meta-analyses, whereas the TUG test was not a significant predictor of falls, being accurate only $57 \%$ of the time. The same study does not support the use of the TUG test as a reliable predictor of falls for older adults in clinical practice ${ }^{25}$. The TUG test showed a mild correlation with age, which might be due to the increased incidence of sarcopenia found in individuals aged 75 and over ${ }^{23}$.

Most participants reported a moderate fatigue level, and approximately $25 \%$ of patients reported a severe fatigue level. In addition, fatigue was correlated to functional outcome measures (Gait mobility and independence in daily life). A study with breast cancer women undergoing chemotherapy also showed a moderate correlation between fatigue and functional impairment which was evaluated with a scale that considered impairment in work, home management, social activities, private leisure activities, and relationships ${ }^{26}$. Another study with older adults receiving chemotherapy for solid malignancies also showed a correlation between fatigue and functional status measured with the indicator dependence on instrumental activities of daily life ${ }^{27}$.

Fatigue is an important subject for adults with cancer, which is characterized by the chronicity of this symptom, itself considered a disagreeable, harrowing sensation, and a life-limiting experience ${ }^{28,29}$. Patients with fatigue often report tiredness, cognitive impairment, sleepiness, mood alterations, and muscle weakness ${ }^{30}$. The literature suggests that a 12-week program of exercise reduces fatigue among patients diagnosed with cancer $^{31}$. Exercise programs should include warm-ups, aerobic training, muscle strengthening pectoralis and lower limbs, stretching, and relaxing, the protocol should be performed twice to three times a week, to $50 \%-80 \%$ of cardiac frequency ${ }^{31}$. Exercise protocols could reduce fatigue, improve strength, balance, and the functional activities of older adults with cancer. Nevertheless, few cancer patients have access to 
exercise programs or rehabilitation ${ }^{32}$. There is a necessity to improve access to rehabilitation that includes physical exercises for older cancer survivors.

We did not find significant correlations between the number of falls/hospitalizations and functional outcomes. Probably other factors related to the aging process, cancer, or its treatments (medications, peripheral neuropathy) might impact more on falls rather than functional outcomes. A Canadian study identified that falls were not commonly reported by older cancer patients nor prioritized by oncologists and falls did not impact their cancer treatment procedures very often ${ }^{33}$.

The strengths of the present study are the fact we included several types of neoplasms in accordance with cancer prevalence in Chile, that we controlled for the cognitive levels of participants to guarantee the full comprehension of assessments that were performed, and that we used valid and reliable instruments. One of the limitations of the present study is the cross-sectional design that does not allow a cause-effect relation. In addition, the survey was conducted in only one hospital in Chile using a consecutive sampling.

\section{Conclusions}

Therefore, we can conclude that the older cancer patients in our study reported moderate fatigue and showed functional impairments: low handgrip strength scores, and a high dependence in daily basic activities, especially those associated with mobility, dressing, and bladder or bowel function. Further studies should address a greater number of participants and perform the survey in several health centers. Health care centers dealing with older cancer patients should add physical exercises to reduce fatigue and the loss of lean body mass and improve independence in daily activities.

\section{References}

1. WHO. Ageing and life-course. Available from https://www. who.int/ageing/about/facts/en/

2. Mancilla Solorza E, Ramos FS, Morales BP. Fuerza de prensión manual según edad, género y condición funcional en adultos mayores chilenos entre 60 y 91 años. Rev Med Chile. 2016;144:598-603. https://doi.org/10.4067/S003498872016000500007

3. Bray F, Ferlay J, Soerjomataram I, Siegel RL, Torre LA, Jemal A. Global cancer statistics 2018: GLOBOCAN estimates of incidence and mortality worldwide for 36 cancers in 185 countries. CA: Cancer J Clin. 2018; 68(6), 394-424. doi:10.3322/caac. 21492

4. NIH. National Cancer Institute USA. Side Effects of Cancer Treatment. Retrieved from https://www.cancer.gov/aboutcancer/treatment/side-effects. Accessed 6 Feb 2020

5. Li D, Soto-Perez-de-Celis E, Hurria A. Geriatric Assessment and Tools for Predicting Treatment Toxicity in Older
Adults with Cancer. Cancer J. 2017;23:206-10. https://doi. org/10.1097/PPO.0000000000000269

6. Pollock Y, Chan CL, Hall K, Englesbe M, Diehl KM, Min L. A novel geriatric assessment tool that predicts postoperative complications in older adults with cancer. J Geriatr Oncol. 2019 (4): S1879-4068. doi: 10.1016/j. jgo.2019.09.013

7. Morley JE, Vellas B, Kan G, Vanker SD, Bauer JM, Barnabei R et al. Frailty consensus: a call to action. J Am Med Dir Assoc. 2013;14(6):392-7. doi: 10.1016/j.jamda.2013.03.022

8. Brown JC, Harhay MO, Harhay MN. Self-reported major mobility disability and mortality among cancer survivors. J Geriatr Oncol. 2018;9:459-63. https://doi.org/10.1016/j. jgo.2018.03.004

9. Paek J, Choi YJ. Association between handgrip strength and impaired health-related quality of life in Korean cancer survivors: A cross-sectional study. BMJ Open. 2019;9(9):1-8. doi:10.1136/bmjopen-2019-030938

10. Presley CJ, Canavan M, Wang SY, et al. Severe functional limitation due to pain \& emotional distress and subsequent receipt of prescription medications among older adults with cancer. J Geriatr Oncol. 2020;11(6):960-8. doi:10.1016/j. jgo.2020.02.006

11. Galvin A, Helmer C, Coureau G, Amadeo B, Rainfray, Soubeyran $\mathrm{P}$ et al. Determinants of functional decline in older adults experiencing cancer (the INCAPAC study). J Geriatr Oncol. 2019;10(6):913-20. doi:10.1016/j.jgo.2019.03.006

12. Mathiowetz V, Vizenor L, Melander D. Comparison of Baseline Instruments to the Jamar Dynamometer and B\&L Engineering Pinch Gauge. Occup Ther J Res. 2000; 20:14762. https://doi.org/10.1177/153944920002000301

13. Mahoney Fi, Barthel DW. Functional Evaluation: The Barthel Index. Md State Med J. 1965;14:61-5.

14. Sainsbury A, Seebass G, Bansal A, Young JB. Reliability of the Barthel Index when used with older people. Age Ageing. 2005;34:228-32

15. Shumway-Cook A, Brauer S, Woollacott M. Predicting the Probability for Falls in Community-Dwelling Older Adults Using the Timed Up \& Go Test. Phys Ther. 2000;80:896903. https://doi.org/10.1093/ptj/80.9.896

16. Ministerio de Salud de Chile. Plan Nacional del Cancer 2018-2028. Retrieved from https://www.minsal.cl/wp-con tent/uploads/2019/01/2019.01.23_PLAN-NACIONAL-DECANCER_web.pdf. Accessed 6 Feb 2020.

17. Mendoza TR, Wang XS, Cleeland CS, Morrissey M, Johnson BA, Wendt JK et al. The rapid assessment of fatigue severity in cancer patients. Cancer. 1999;85:1186-96. doi. org/10.1002/(SICI)1097-0142(19990301)85:5 < 1186:: AID-CNCR24 > 3.0.CO;2-N.

18. Lorca LA, Sacomori C, Puga B. Propiedades psicométricas del inventario breve de fatiga en personas tratadas por neoplasias hematológicas en Chile. Rev Med Chile. 2016;144:894-9. https://doi.org/10.4067/S003498872016000700010

19. Gebremariam GT, Anshabo AT, Tigeneh W, Engidawork E. Validation of the Amharic version of the Brief Fatigue Inventory for Assessment of Cancer-Related Fatigue in Ethiopian Cancer Patients. J Pain Symptom Manage. 2018;56:264-72. https://doi.org/10.1016/j.jpainsym man.2018.04.015 
20. Manrique-Espinoza B, Salinas-Rodríguez A, Avila-Funes A. Sarcopenia is associated with physical and mental components of quality of life in older adults validation of a cutoff point for the short version (7-item) of the Depression Scale of the Center for Epidemiological Studies in Mexican elderly View project Global Geriatric Oncology View project. J Am Med Dir Assoc. 2017;18:636e. https://doi.org/ 10.1093/geroni/igx004.2807

21. Durán SA, Mattar AP, Bravo BN, Moreno C, Reyes S. Asociación entre calidad de vida y cantidad de sueño en adultos mayores de la Región Metropolitana y Región de Valparaíso, Chile. Rev Med Chile. 2014;142:1371-6. https://doi. org/10.4067/S0034-98872014001100002

22. Bahat G, Tufan A, Tufan F, Kilic C, Akipinar T, Kose M, et al. Cut-off points to identify sarcopenia according to European Working Group on Sarcopenia in Older People (EWGSOP) definition. Clin Nutr. 2016;35:1557-63. https:// doi.org/10.1016/j.clnu.2016.02.002

23. Riviati N, Setiati S, Laksmi PW, Abdullah M. Factors Related with Handgrip Strength in Elderly Patients. Acta Med Indones. 2017;49:215-19.

24. Alkan $\ddot{8} B$, Artaç M, Rakıcıoğlu N. The relationship between nutritional status and handgrip strength in adult cancer patients: a cross-sectional study. Support Care Cancer. 2018; 26:2441-51. https://doi.org/10.1007/s00520-0184082-8

25. Barry E, Galvin R, Keogh C, Frances H. Is the Timed Up and Go test a useful predictor of risk of falls in communitydwelling older adults: A systematic review and meta-analysis. BMC Geriatr. 2014;14. doi.org/10.1186/1471-2318-1414

26. Hughes A, Suleman S, Rimes KA, Marsden J, Chalder T. Cancer-related fatigue and functional impairment - Towards an understanding of cognitive and behavioural factors. $\mathrm{J}$ Psychosom Res. 2020;134:110127. doi:10.1016/j.jpsychores.2020.110127

27. Luciani A, Jacobsen PB, Extermann M, Foa P, Marussi D, Ferrari D, et al. The impact of fatigue and anemia on functional status in older cancer patients treated with chemotherapy. J Geriatr Oncol. 2012;3(3):182-88. doi:10.1016/ j.jgo.2012.02.004
28. Servaes P, Verhagen C, Bleijenberg G. Fatiga en pacientes con cáncer, durante y después del tratamiento: prevalencia, factores correlacionados e intervenciones. Eur J Cancer (Ed. Española), 2002;2, 151-68.

29. Mock V, Atkinson A, Barsevick A, Cella D, Cimprich B, Cleeland C, et al. NCCN Practice Guidelines for CancerRelated Fatigue. Oncology (Williston Park). 2000;14 (11A):151-61.

30. Font A, Rodríguez E, Buscemi V. Fatiga, Expectativas y Calidad de Vida en Cáncer. Psicooncología. 2004;(1):45-56.

31. Meneses-Echavez J, González-Jimenez E, Correa-Bautista J, Schmidt-Rio Valle J, Ramirez-Velez R. Efectividad del ejercicio físico en la fatiga de pacientes con cáncer durante el tratamiento activo: revisión sistemática y metaanálisis. Cad. Saúde Pública. 2015;31(4), 667-81.

32. Pergolotti M, Lyons KD, Williams GR. Moving beyond symptom management towards cancer rehabilitation for older adults: Answering the 5W's. J Geriatr Oncol. 2018;9 (6):543-9. doi:10.1016/j.jgo.2017.11.009

33. Sattar S, Alibhai SMH, Spoelstra SL, Puts MTE. The assessment, management, and reporting of falls, and the impact of falls on cancer treatment in community-dwelling older patients receiving cancer treatment: Results from a mixed-methods study. J Geriatr Oncol. 2019;10(1):98-104. doi:10.1016/j.jgo.2018.08.006.

\section{Corresponding author}

Cinara Sacomori, Universidad Bernardo O’Higgins, Escuela de Kinesiología. Av. Viel 1497, Santiago, Chile. E-mail: csacomori@yahoo.com.br.

Manuscript received on November 12, 2020

Manuscript accepted on February 22, 2021



Motriz. The Journal of Physical Education. UNESP. Rio Claro, SP, Brazil - eISSN: 1980-6574 - under a license Creative Commons - Version 4.0 